\title{
PENGARUH PENDIDIKAN KESEHATAN TENTANG MENSTRUASI TERHADAP KESIAPAN PSIKOLOGIS DALAM MENGHADAPI MENARCHE PADA REMAJA PUTRI PRAPUBERTAS DI SD GUGUS V MENGWI
}

\author{
Ni Gusti Ayu Pramita Aswitami ${ }^{1}$ \\ ${ }^{1}$ STIKES Bina Usada Bali \\ Diterima : 1 Oktober 2018 , Disetujui : 24 Oktober 2018 \\ e-mail: tami_chant@yahoo.com
}

\begin{abstract}
Background: Menarche is the first menstruation out in young women. Menarche occurs in young women who have entered the puberty phase. Often young women are not ready to face menarche, this is due to a lack of information about menstruation and preparations that must be done in the face of menstruation. With conditions that are not ready, young women often feel anxious and fearful, thus disrupting psychology and hindering daily activities. To prepare young women in the face of menarche, it is necessary to provide information correctly and right before teenage poetry enters puberty, the prepubertal period. This information can be provided through health education. through health education, young women are better prepared and not anxious and afraid when experiencing menarche. The aim of the study was to determine the effect of health education on menstruation on psychological readiness in the face of menarche in prepubertal adolescent girls in SD Gugus V Mengwi. Method: This research is a quasy-experimental study, the design of the research used is the Pre-test and Post-test One Group Design that is looking at the differences before and after the intervention. Samples taken were 79 class $V$ students who had not experienced menarche at the SD Gugus V Mengwi V.The sampling technique is total sampling. Data collection was carried out using a questionnaire that had been tested for validity and reliability. Statistical analysis using the Wilcoxon Match Pairs Test. Results : this study indicate that there is an influence of health education about menstruation on psychological readiness in the face of menarche in prepubertal girls in the Gwi Cluster $V$ Elementary School. Conclusion: It is suggested to young women to increase their knowledge, awareness, and concern for the health of their reproductive functions, especially in the face of menarche after being given health education about menarche so that good readiness can be achieved when facing menarche.
\end{abstract}

Keywords: Menarche, Health Education

\section{PENDAHULUAN}

Menarche merupakan menstruasi pertama yang biasanya terjadi dalam rentang usia 10-16 tahun atau pada remaja awal. Menarche merupakan suatu tanda awal adanya perubahan lain seperti pertumbuhan payudara, pertumbuhan rambut daerah pubis dan aksila, serta distribusi lemak pada daerah pinggul (Efendy, 2007). Pada remaja menarche adalah suatu keadaan yang membuat cemas dan takut karena kurangnya kesiapan para remaja untuk masuk fase pubertas. Kebanyakan para remaja akan menolak proses fisiologi tersebut (Kartono, 2006), umumnya karena kurang 
atau salah informasi mengenai menstruasi. Maka dari itu remaja putri membutuhkan informasi tentang proses menstruasi dan kesehatan selama menstruasi, karena remaja putri akan mengalami kesulitan dalam menghadapi menstruasi jika sebelumnya ia belum pernah mengetahui atau membicarakannya dengan teman sebaya atau dengan ibu mereka karena jika sudah dipersiapkan dari awal, biasanya tidak bingung lagi menghadapi menarche (Mayasari, 2008).

Menurut penelitan terhadap partisipan dari 23 negara sepertiga responden mengatakan mereka tidak diberitahu tentang menstruasi sebelumnya sehingga tidak siap dan tidak tahu apa yang harus dilakukannya. Dari survei tersebut mereka yang tidak pernah tahu masalah menstruasi, para remaja itu mengatakan hal ini merupakan pengalaman yang sangat buruk dan menstruasi pertama membuat panik, traumatik, malu dan takut (BKKBN, 2000). Untuk persiapan menghadapi menarche, maka remaja baiknya diberikan informasi pada masa prapubertas. Prapuber adalah satu atau dua tahun sebelum masa remaja yang sesungguhnya, anak menjadi gemuk, pertumbuhan tinggi badan terhambat sementara (Rumini, 2004). Prapuber adalah tahap pematangan yaitu pada satu atau dua tahun terakhir masa kanakkanak. Pada masa ini anak disebut prapuber sehingga ia tidak disebut seorang anak kecil ataupun remaja. Pada tahap ini ciri-ciri seks sekunder mulai tampak namun organ-organ reproduksinya belum berkembang secara sempurna (Mighwar, 2006) .Pada saat prapuber dan pubertas, informasi tentang reproduksi merupakan hal penting untuk menjalani fase kehidupannya dan melaksanakan tugas perkembangannya. Kurangnya informasi tentang reproduksi khususnya menstruasi pada remaja putri dapat berdampak terhadap kesiapan dalam menghadapi menarche Kesiapan atau ketidaksiapan menghadapi menarche berdampak terhadap reaksi individual remaja putri saat menstruasi pertama berdampak positif dan negatif (Miftah, 2009).Informasi tentang proses menstruasi salah satunya dapat diperoleh dari pendidikan kesehatan. Pendidikan tentang kesehatan reproduksi merupakan masalah penting yang perlu mendapat perhatian khusus dari semua pihak. Bentuk penyampaian informasi kesehatan reproduksi remaja tidak harus secara "vulgar", tetapi bisa dilakukan pendekatan bermacam-macam dan disesuaikan dengan nilai dan norma yang berlaku di masyarakat indonesia. Salah satunya dengan mengembangkan forum diskusi dalam bentuk pemberian pendidikan kesehatan (Miftah, 2009). Menurut Boyke (2009), sebaiknya pendidikan kesehatan di masukkan kedalam kurikulum sekolah sehingga remaja sadar bagaimana organ reproduksinya agar tetap sehat dan mempunyai kesiapan menghadapi menarche.

Berdasarkan studi pendahuluan melalui wawancara terhadap Kepala Sekolah dan Guru Usaha Kesehatan Sekolah (UKS) di SD Gugus V Mengwi, mengatakan bahwa siswi kelas $\mathrm{V}$ belum pernah mendapatkan informasi tentang kesehatan reproduksi, dan masih sering menemukan siswinya menangis ketika menarche dan gangguan menstruasi. Sedangkan dari hasil wawancara dengan 10 siswi kelas $\mathrm{V}$, didapatkan $3(30 \%)$ siswi yang sudah siap menghadapi menstruasi dan 7 (70\%) siswi yang masih 
takut dan belum siap menghadapi menarche. Berdasarkan dari hal diatas maka tujuan penelitian ini adalah untuk mengetahui apakah ada pengaruh pendidikan kesehatan tentang menstruasi terhadap kesiapan psikologi dalam menghadapi menarche pada remaja putri prapubertas.

\section{METODE PENELITIAN}

Metode penelitian yang digunakan dalam penelitian ini adalah penelitian quasi experiment (eksperimen semu) yang merupakan kegiatan percobaan bertujuan untuk mengetahui suatu gejala pengaruh yang timbul (Notoatmodjo, 2005). Penelitian ini menggunakan rancangan penelitian Pre-test and Posttest One Group Desain, yaitu melihat perbedaan sebelum dan sesudah intervensi tanpa adanya kelompok kontrol(Arikunto, 2006). Pada penelitian ini dilakukan pengukuran kesiapan psikologi remaja putri sebelum dan sesudah perlakuan. Pengukuran kesiapan psikologi dilakukan dengan memberikan kuesioner yang telah diuji validitas dan uji reliabilitasnya. Setelah penelitian dilakukan analisis data untuk melihat apakah ada pengaruh pendidikan kesehatan tentang menarche terhadap kesiapan psikologi dalam menghadapi menarche pada remaja putri prapubertas.

Tehnik pengambilan sampel secara total sampling dengan jumlah sampel 79 siswa putri yang belum mengalami menarche. Penelitian ini dilakukan pada bulan Maret - April 2016 di SD Gugus V Mengwi.

\section{HASIL PENELITIAN}

\section{Analisis Univariat}

a. Karakteristik responden berdasarkan kesiapan awal responden (Pre-test).

Tabel 1. Distribusi Frekuensi Kesiapan Psikologis Remaja Putri Prapubertas sebelum intervensi di SD Gugus V Mengwi

\begin{tabular}{ccc}
\hline $\begin{array}{c}\text { Tingkat } \\
\text { Kesiapan }\end{array}$ & Frekuensi & Persentase ( \%) \\
\hline Siap & 64 & 81,0 \\
Tidak Siap & 15 & 19,0 \\
\hline Total & 79 & 100 \\
\hline Berdasarkan & Tabel
\end{tabular}

menggambarkan kesiapan responden sebelum intervensi (pre-test) dari 79 responden dalam penelitian ini yang siap sebanyak 64 orang $(81,0 \%)$ dan yang tidak siap ada 15 orang $(19,0 \%)$. Jadi kesiapan responden sebelum intervensi lebih banyak yang siap menghadapi menarche yaitu $(81,0 \%)$.

b. Karakteristik responden berdasarkan kesiapan responden setelah intervensi (Post-test).

Tabel 2. Distribusi Frekuensi Kesiapan Psikologis Remaja Putri Prapubertas sesudah intervensi di SD Gugus V Mengwi

\begin{tabular}{|c|c|c|}
\hline $\begin{array}{c}\text { Tingkat } \\
\text { Kesiapan }\end{array}$ & Frekuensi & Persentase $(\%)$ \\
\hline Siap & 74 & 93,7 \\
\hline $\begin{array}{l}\text { Tidak } \\
\text { Siap }\end{array}$ & 5 & 6,3 \\
\hline Total & 79 & 100 \\
\hline
\end{tabular}

menggambarkan kesiapan responden sesudah intervensi (post-test) dari 79 responden dalam penelitian ini yang siap 74 orang $(93,7 \%)$, dan yang tidak siap ada 5 orang $(6,3 \%)$. Jadi kesiapan responden sesudah intervensi lebih banyak yang siap menghadapi menarche yaitu $(93,7 \%)$. 


\section{Analisis Bivariat}

Tabel 3. Distribusi Frekuensi Kesiapan Psikologis Remaja Putri Prapubertas Sebelum dan Sesudah Intervensi di SD Gugus V Mengwi

\begin{tabular}{llllll}
\hline & Mean & $\begin{array}{l}\text { Rata- } \\
\text { rata } \\
\text { peningk } \\
\text { atan } \\
\text { mean }\end{array}$ & SD & $\mathbf{Z}$ & $\begin{array}{l}\text { P- } \\
\text { Val } \\
\text { ue }\end{array}$ \\
\hline $\begin{array}{l}\text { Pre } \\
\text { Test }\end{array}$ & 17.17 & & 4.22 & \\
\hline & & 1,35 & & & \\
\hline $\begin{array}{l}\text { Post } \\
\text { Test }\end{array}$ & 18.53 & & 3.28 & - & 0,01 \\
\hline & Pada & tabel & 3 & menggambarkan
\end{tabular}

hasil analisis data dengan uji Wilcoxon Match Pairs Test diperoleh nilai signifikan sebesar 0,010 lebih kecil dari pada $\alpha$, jadi dapat disimpulkan bahwa ada pengaruh Pendidikan Kesehatan tentang Menstruasi terhadap Kesiapan Psikologis dalam Menghadapi Menarche pada Remaja Putri Prapubertas di SD Gugus V Mengwi.

\section{PEMBAHASAN}

\section{Gambaran kesiapan psikologis remaja putri prapubertas menghadapi menarche sebelum diberi pendidikan kesehatan.}

Seorang remaja dikatakan siap menghadapi menarche apabila remaja telah siap secara psikis menghadapi menarche. Seorang remaja siap secara psikis apabila remaja tersebut menganggap menstruasi adalah hal yang normal yang tidak membebani pikirannya hal ini ditandai dengan percaya diri, tidak takut, tidak cemas dan mau menerima keadaannya sebagai wanita yang harus mengalami menstruasi (Kartono, 2006). Berdasarkan hasil penelitian di SD Gugus V Mengwi sebelum di berikan pendidikan kesehatan dari 79 orang menunjukkan 64 orang $(81,0 \%)$ siap menghadapi menarche.

Hal ini menunjukkan bahwa sebagian besar responden siap menghadapi menarche karena mereka ada yang sudah mendapat informasi tentang menstruasi dari orang tua mereka tentang bagaimana jika menstruasi tiba-tiba datang, kemudian dari majalah-majalah remaja karena pada zaman sekarang anakanak remaja putri sudah memiliki wawasan yang sedikit lebih maju dari anak-anak remaja putri pada zaman dulu hal ini disebabkan oleh keingintahuan mereka yang besar dengan mencari informasi dari internet, televisi atau dari teman sebaya seperti hal-hal yang harus diperhatikan saat menstruasi khususnya perawatan diri selama menstruasi, juga cara mengganti pembalut setiap hari saat menstruasi. Selain itu mereka juga menganggap menstruasi adalah hal yang normal yang akan dialami oleh setiap wanita yang akan dewasa, serta mereka tidak merasa malu ketika menghadapi menarche.

Sedangkan berdasarkan hasil penelitian di SD Gugus V Mengwi sebelum di berikan pendidikan kesehatan dari 79 orang menunjukkan 15 orang $(19,0 \%)$ tidak siap menghadapi menarche. Responden mengatakan tidak siap karena responden tidak diberitahu tentang menstruasi sebelumnya sehingga tidak siap dan tidak tahu apa yang harus dilakukannya. Dari survei yang dilakukan partisipan dari 23 negara bahwa sepertiga responden tidak pernah tahu masalah tentang menstruasi, para remaja itu mengatakan hal ini merupakan pengalaman yang sangat buruk dan menstruasi pertama membuat panik, traumatik, malu dan takut (BKKBN, 2000). Kesiapan remaja putri prapubertas 
menghadapi menarche juga dipengaruhi oleh beberapa hal antara lain semakin tinggi pendidikan seseorang maka akan semakin mudah dan siap mengalami perubahan termaksud datangnya menstruasi, apabila usia terlalu muda akan sulit menerima hal baru dalam hidup seperti datangnya menarche, serta lingkungan sekitar juga penting dan sangat berpengaruh untuk perubahan remaja putri, informasi sebelum menstruasi sangat penting untuk diterima remaja putri sebelum menarche. Karena apabila di bekali dengan pengetahuan dan pemahaman yang benar tentang alat reproduksi maka remaja putri tidak akan merasa takut menghadapi menarche. Menurut Notoatmodjo (2003) bahwa pengetahuan yang dimiliki oleh seseorang akan sangat berpengaruh terhadap kesiapan seseorang. Pengetahuan itu sendiri dapat diperoleh dengan cara diberikan pendidikan kesehatan. Pendidikan kesehatan didefinisikan sebagai penerapan pendidikan dalam bidang kesehatan dimana diharapkan ada perubahan perilaku untuk memelihara dan meningkatkan kesehatan yang kondusif. Pendidikan kesehatan dilakukan untuk memberikan pengetahuan tentang kesehatan dengan harapan agar remaja putri mampu memberikan pengaruh terhadap kesiapan remaja putri tersebut dalam menghadapi menarche.

Dengan diberikan pendidikan kesehatan ini akan berpengaruh pada pengetahuan, sehingga memperluas pengetahuan remaja putri sehingga akan meningkatkan pengetahuan tentang menarche. Dengan pengetahuan yang benar ini akan berpengaruh pada kesiapan remaja putri prapubertas menghadapi menarche.

\section{Gambaran kesiapan psikologis remaja putri prapubertas menghadapi menarche setelah diberi pendidikan kesehatan.}

Berdasarkan hasil penelitian di SD

Gugus V Mengwi setelah diberikan pendidikan kesehatan tentang pengertian menstruasi, cara merawat diri saat menstruasi, cara mengatasi gangguangangguan pada saat menstruasi terjadi peningkatan kesiapan remaja dalam menghadapi menarche dari 79 orang menunjukkan 74 orang $(93,7 \%)$ siap menghadapi menarche. Dari hasil penelitian tersebut terjadi peningkatan setelah diberikan pendidikan kesehatan di karena sebagian besar responden sudah siap menghadapi menarche karena remaja tersebut akan menerima kodrat nya sebagai seorang wanita yang harus mengalami menstruasi, tidak takut dan malu jika mengalami menstruasi, serta mengetahui apa yang harus dilakukan saat menstruasi, selain itu juga menganggap menstruasi adalah hal yang normal yang pasti akan dialami oleh setiap wanita yang akan dewasa dan menerima keadaannya sebagai wanita yang akan mengalami menstruasi.

Pendidikan kesehatan dilakukan untuk memberikan pengetahuan tentang menarche pada remaja putri sebelum menstruasi. Dengan harapan agar remaja putri yang diberikan pendidikan kesehatan siap bila menstruasi tiba-tiba datang. Sedangkan berdasarkan hasil penelitian di SD Gugus V Mengwi setelah diberikan pendidikan kesehatan dari 79 orang menunjukkan 5 orang $(6,3 \%)$ tidak siap menghadapi menarche. Hal ini dikarenakan remaja tersebut masih bingung dan sulit untuk menerima pesan dan keadaan pikiran serta persiapan diri remaja putri untuk menghadapi menarche 
sebagai peristiwa emosi dapat mempengaruhi persepsi terhadap dirinya sendiri dan reaksinya terhadap menstruasi selanjutnya.

Menarche

memerlukan

penyesuaian diri yang sulit selama prapubertas dan berhubungan dengan respon emosional yang kuat, baik positif maupun negatif (Kartono, 2006). Dalam penelitian ini menunjukkan bahwa ada peningkatan kesiapan remaja putri prapubertas menghadapi menarche dari $(81,0 \%)$ sebelum diberikan pendidikan kesehatan tentang menstruasi menjadi $(93,7 \%)$ setelah diberi pendidikan kesehatan tentang menstruasi. Peningkatan kesiapan menghadapi menarche sesuai dengan tujuan pendidikan kesehatan yaitu meningkatkan pengetahuan dan keterampilan serta mengubah sikap dan perilaku remaja putri yang mempunyai pengetahuan tentang menstruasi maka akan mudah memahami perubahanperubahan fisiologis yang menyebabkan ketidakstabilan psikologis sehingga remaja lebih siap menghadapi menarche. Akan tetapi ada beberapa faktor yang mempengaruhi pendidikan kesehatan antara lain bahasa, jika bahasa yang digunakan jelas dan tidak monoton dan disertai dengan bahasa anak remaja maka pendidikan kesehatan akan lebih menarik.

\section{Pengaruh Pendidikan Kesehatan tentang Menstruasi terhadap Kesiapan Psikologis dalam Menghadapi Menarche pada Remaja Putri Prapubertas}

Pengaruh pendidikan kesehatan tentang menstruasi terhadap kesiapan psikologis menghadapi menarche antara sebelum diberikan dan setelah diberikan pendidikan kesehatan menunjukkan hasil bahwa ada peningkatan kesiapan psikologis. Pada saat sebelum diberikan pendidikan kesehatan ada $(19,0 \%)$ remaja putri yang tidak siap menghadapi menarche dan menurun menjadi $(6,3 \%)$ yang belum siap menghadapi menarche setelah diberikan pendidikan kesehatan. Hal ini berarti sesuai dengan pendapat yang dikemukakan Effendy (1998) yang mengatakan bahwa tujuan dari pendidikan kesehatan adalah tercapainya perubahan perilaku individu, keluarga dan masyarakat dalam membina dan memelihara perilaku lingkungan sehat serta berperan aktif dalam mewujudkan derajat kesehatan yang optimal. Dari hasil uji statistik Wilcoxon Match Pairs Test dengan toleransi level signifikasi ditetapkan sebesar $\alpha=0,05$ dan didapatkan nilai sebesar 0,010 lebih kecil dari $\alpha$ jadi dapat dijelaskan bahwa ada pengaruh pendidikan kesehatan tentang menstruasi terhadap kesiapan psikologis dalam menghadapi menarche pada remaja putri prapubertas di SD Gugus V Mengwi.

Hal ini disebabkan oleh karena pada umumnya sebelum diberikan pendidikan kesehatan tentang menstruasi mereka masih ada yang tidak siap meghadapi menstruasi hal ini ditandai oleh pengetahuan yang kurang tentang menstruasi, dan persepsi terhadap diri remaja putri yaitu penerimaan seperti anggapan bahwa menstruasi merupakan hal yang normal yang terjadi pada setiap wanita yang akan dewasa dan merupakan suatu penyakit. Hal ini sesuai dengan pendapat yang dikemukakan Rubiyanto (2007), bahwa dengan pemahaman yang benar tentang alat reproduksi, maka remaja putri tidak akan merasa takut menghadapi menstruasi. Dan dari hasil penelitian diatas menunjukkan bahwa informasi tentang menarche dapat 
meningkatkan tingkat kesiapan bagi responden, semakin tinggi informasi yang didapat maka tingkat kesiapan psikologis anak perempuan akan semakin tinggi dalam menghadapi menarche. Pendidikan kesehatan secara langsung sangat berpengaruh pada peningkatan kesiapan psikologis menghadapi menarche sesuai dengan pendapat dari Notoatmodjo (2003) yang menyatakan bahwa penyuluhan dan bimbingan merupakan bagian dari pendidikan kesehatan yaitu suatu kegiatan untuk membantu individu, kelompok/ masyarakat dalam meningkatkan kemampuan (perilaku) nya untuk mencapai kesehatan optimal. Dalam penelitian ini terjadi perubahan kesiapan sesudah diberikan pendidikan kesehatan. Perubahan tersebut dipengaruhi oleh beberapa faktor yaitu apabila tingkat perkembangan psikis remaja putri baik maka menstruasi setiap bulannya berlangsung normal dan usia. Apabila semakin muda usia maka semakin tidak siap remaja putri menerima menstruasi, kemudian semakin tinggi pendidikan maka semakin mudah menerima hal baru dan mudah menyesuaikan dengan hal-hal baru tersebut, serta peran orang tua juga sangat berpengaruh penting untuk memberikan pengetahuan dan pemahaman kepada remaja putri. Pendidikan kesehatan akan sangat membantu remaja untuk mendapatkan informasi yang tepat sehingga dapat mengurangi beban psikologisnya. Selain itu dengan diberikan informasi secara bersama sama dengan teman sebaya, remaja akan lebih mengingat dan tidak malu untuk bertanya serta dapat memberikan pengertian dan persepsi yang sama tanpa ada informasi yang salah. Dengan demikian para remaja akan melalui perubahan-perubahan pada fisik maupun psikisnya dengan baik tanpa ada kecemasan ataupun ketakutan. Pemberian informasi yang tepat dan benar akan membentuk remaja putri lebih percaya diri dan mampu menghadapinya dengan tenang dan bahagia.

\section{KESIMPULAN DAN SARAN}

Berdasarkan hasil uji statistik dapat disimpulkan terdapat pengaruh pendidikan kesehatan tentang menstruasi terhadap kesiapan psikologis dalam menghadapi menarche pada remaja putri prapubertas di SD Gugus V Mengwi yang ditunjukkan dengan nilai signifikan sebesar $0,010<$ dari $\alpha$. Disarankan pada orang tua, pihak sekolah serta tenaga kesehatan untuk lebih mempersiapkan remaja putri dalam menghadapi menarche dengan memberikan informasi yang tepat serta dikemas secara menarik mengenai masa pubertas, menstruasi dan pengenalan lebih dalam tentang alat reproduksi.

\section{DAFTAR RUJUKAN}

Arikunto, S. (2006). Prosedur Penelitian Suatu Pendekatan Praktek. Jakarta: Rineka Cipta.

Chaplin. J. (2002). Kamus Lengkap Psikologi. Jakarta : Raja Grafindo Persada.

Efendy, F. (2007). Koping Adaptasi Menarche Sebagai Strategi Peningkatan Kesehatan Reproduksi Remaja. www.ferryefendy.blogspot.com.

Effendy, N. (1998). Dasar-dasar Keperawatan Masyarakat. Jakarta: EGC.

Hurlock. (2004). Psikologi Perkembangan Sepanjang Daur Hidup Perempuan. Jakarta: Erlangga. 
Kartono, K. (2006). Psikologi Wanita Jilid I Mengenal Gadis Remaja dan Wanita Dewasa. Bandung : Mandar Maju.

Keikoz. (2007). Menstruasi. http: //www.keikoz.biz.

Mayasari, D. (2008). Study Kasus Mengenai Pengetahuan Dan Penerimaan Putri Terhadap Menstruasi. Skripsi. Fakultas Psikologi Indonesia. http://hqweb01.BKKBN.qo.id.

Miftah. (2009). Haid Pertama Datang, Perlukah Takut?. www.kesrepro.info.com

Mighwar, M. (2006). Psikologi Remaja, Petunjuk Bagi Guru dan Orang Tua. Bandung: Pustaka Setia.

Mochtar, Rustam. (1998). Sinopsis Obstetri. Jakarta: EGC.

Nike. (2008). Menarche Pada Remaja Putri. www.pikirdong.com

Notoatmodjo. (2005). Metode Penelitian Kesehatan. Jakarta : Rineka Cipta.

Robert P. Farry. Reability of test scores. www. Testcoring.vt.edv/memo.09 htm5

Rubiyanto. (2007). Menstruasi, Matanya Organ Perempuan. Written by Lovemoon Indonesi

Rumini. (2004). Perkembanagn Anak Dan Remaja. Jakarta : Rineka Cipta

Sofyan. (2003). 50 Tahun IBI Bidan Menyongsong Masa Depan. Jakarta : Pengurus Pusat IBI.

Sugiyono. (2006). Statistika Untuk Penelitian. Bandung : Alfabeta

Sugiyono. (2008). Metode Penelitian Pendidikan. Bandung: Alfabeta

Wiknjosastro. (2002). Ilmu Kandungan. Jakarta: Yayasan Bina Pustaka Sarwono Prawirohardjo. 